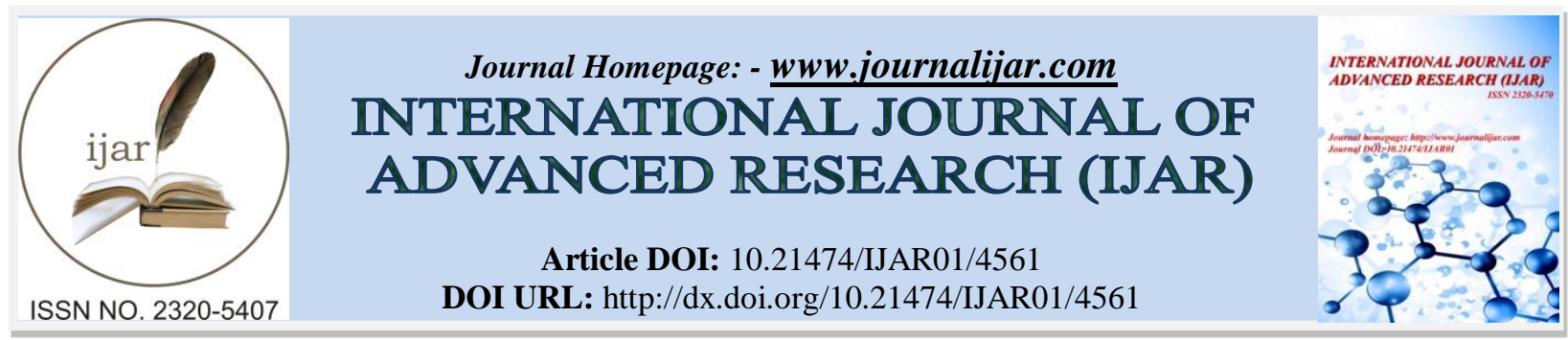

RESEARCH ARTICLE

\title{
SELF-PERCEPTION OF THE ELDERLY'S QUALITY OF LIFE AS A BASIS FOR THEIR INTEGRAL
} FUNCTIONING.

\author{
Luz Virginia Pacheco Quijano ${ }^{1}$, Betty Sarabia Alcocer ${ }^{2}$, Ana Rosa Can Valle ${ }^{3}$, Jaqueline Guadalupe \\ Guerrero $\mathrm{Ceh}^{3}$, Liliana García Reyes ${ }^{1}$, Gabriela Perez Aranda ${ }^{1}$, Sinuhe Estrada Carmona ${ }^{1}$, Cindy Rossina \\ Saravia Lopez ${ }^{1}$ and Alondra S. Alpuche Reyes ${ }^{1}$. \\ 1. Faculty of Humanities, Autonomous University of Campeche. \\ 2. Faculty of Medicine, Autonomous University of Campeche, Av. Patricio Trueba de Regil s/n, Col. Lindavista \\ C:P: 24090 Campeche, Camp., Mexico \\ 3. School of Nursing, Autonomous University of Campeche.
}

\section{Manuscript Info}

Manuscript History

Received: 21 April 2017

Final Accepted: 23 May 2017

Published: June 2017

Key words:-

Old age, Self-concept, Self-perception, Quality of Life, Senior Citizen.

\section{Abstract}

Self-perception is a basic element in the integral functioning of the older adult in which transitions of a psychosocial type are generated, affecting their lifestyle by the increase of agents that accompany this stage, such as context, family, economic factors, Cultural and political changes and all those actions that directly or indirectly allude to their self-concept. Hence the following question: What is the selfperception of the quality of life of the elderly? The general objective of this work is to determine the self-perception about the quality of life of the older adult who attends the Polvorín Community Center to carry out intervention actions that improve their living conditions according to their real needs in order to achieve comprehensive care and foster their self-care. It is a non-experimental, quantitative approach, of descriptive cross-sectional type. The sample was obtained by intentional non-probabilistic sampling, composed of 50 older adults of which 28 were women (56\%), and 22 were men (44\%). The instrument called the Brief Questionnaire on Quality of Life (CUBRECAVI), was used (Fernández-Ballesteros and Zamarrón, 2007), which measures the quality of life in a multidimensional way through nine components defined according to the aspects that may affect the quality of life, the life of the people and an in-depth interview based on that questionnaire. We find that aging is selfperceived by the elderly as positive, since their functional abilities allow them to take care of themselves and even care for another family member, they feel loved by their family, most of them work in various activities and this allows them to remain socially integrated. economically productive and physically active although most suffer from blood pressure and diabetes. He has a good self-perception of his positive quality of life, this is explained in affirmations where he gives more importance to being than to doing or having. There are differences between men and women in certain scales evaluated by CUBRECAVI, so that women obtain scores indicative of a higher 
quality of life in the components of health, social integration and functional skills, as well as less complaints On different physical symptoms and greater independence than men. Men scored higher than women in the activity and leisure component and environmental quality. Both groups are satisfied with their quality of life. These results allow us to know the reality of the way in which the adult person is perceived and demonstrate that they should continue with the activities that they perform in the club of the Elderly since the workshops in which the older adults participate according to their preferences strengthen them and promote the development of their individual role and it is necessary to implement networks with which the older adult counts to sustain their daily lives. To integrate the older adult in some tasks that he himself considers capable of carrying out and teaching others. As well as training regarding social skills and mechanisms of adaptation of older adults against losses in physical, psychological and social aspects.

Copy Right, IJAR, 2017,. All rights reserved.

\section{Introduction:-}

Mexico currently faces one of the most important challenges of aging its population, there are currently more people over 60 than under 4 and it is expected that by 2050 women over 60 will represent $23.3 \%$ of the total population. The female population and men will constitute $19.5 \%$ of the total of the male population. Demographic projections indicate that in Mexico, the number of older adults in the country will quadruple, from 6.7 million in 2000 to 36.5 million in 2050 (National Population Council, 2013). This demographic development, in which the elderly are already an important part of the population, and great efforts have been made in recent years to improve the quality of life of the elderly. However, it is necessary to recognize that the shortcomings are still numerous and that the future effort must be substantially greater if it is to respond in an integral way to the needs felt by this large population.

The present research arises from the need to know the current situation of the elderly adult campechanos who attend the Club of the Elderly, since on the basis on this intervention actions to improve their living conditions according to their real needs, in order to achieve comprehensive care and to promote self-care in the elderly, as one of the strategies that the Secretariat of Social Development within the program Attention to adults over 70 and over. This program emphasizes in its mission "Contribute to improve the Living conditions of adults over 70 and over, favoring their integration into family and community life, fostering their incorporation into productive activities and fostering a health culture in them, through advocacy and social participation and Granting of economic support ". (National Institute of Public Health, 2012)

During the third age a series of neurobiological; physical, psychological, familiar and social factors that demand personal resources of the elderly, which help him to achieve the adaptation in this stage of life, before the biological, psychological losses and social changes lived by the elderly, their self-concept can be altered. It is important to analyze the perception of oneself during this stage of life and to observe their relation with the well-being in the third age. (Garcia Hernández, 2006).

The World Health Organization (2004) points out that it is no longer enough to live longer, it is now imperative to live them in the best health conditions, understood not only as the absence of disease, but as the complete state of physical well-being, Mental and social. Aging is itself a process whose quality is directly related to how the person meets their needs throughout their entire life cycle. Quality of Life is an individual's perception of their position in life, in the cultural context and the value system in which they live, in relation to their goals, objectives, expectations, values and concerns (World Health Organization, 2014)

The quality of life in old age has to do with economic security and with social inclusion that is ensured through support infrastructures and social networks. All of this will promote the participation of older persons as active members of the community, one of whose functions may be to transmit their experiences to younger generations, while understanding their lifestyle and the challenges that are theirs. The quality of life in older adults can be 
defined as: "that which is based on the quiet and safe enjoyment of health and education, adequate food and decent housing, a stable and healthy environment, Justice, equality between the sexes, responsibility for daily life, dignity and security. (INAPAN, 2010)

For Fernández-Ballesteros the quality of life is a multidimensional concept so that there are different aspects that determine it in each person, among which are the socio-environmental and personal conditions; For purposes of study quality of life is divided into objective and subjective (Fernández-Ballesteros and Zamarrón, 2007). This author Fernández Ballesteros, et al. (1999), presents a model through which it is possible to integrate the personal and socio - environmental dimensions and the subjective and objective elements involved in the quality of life of the elderly: in the Physical, Social and Psychological dimensions and considers the dimensions Which comprehensively and comprehensively comprehend the quality of life. In the Physical Dimension, health status is one of the most important aspects since it influences all aspects of our life. A poor health condition makes individuals dependent, as it is with loss of vision / hearing, sleep and motor pathologies in varying degrees. The psychological effect it produces is isolation and insecurity in itself which makes it difficult to interact with other people. The insecurities and fear of leaving his own home are increased by the deterioration of the vestibular senses, which cause psychomotor uncoordination with slower reaction times, the feeling of not being able to dominate his body in a strange environment as a more important psychological effect Isolation and insecurity in itself which makes it difficult to interrelate with other people. The insecurities and fear of leaving his own home are increased by the deterioration of the vestibular senses, which cause psychomotor uncoordination with slower reaction times, the feeling of not being able to dominate his body in a strange environment. Mauk (2008) considers that aging can be self-perceived as positive when there is personal and functional autonomy, pleasant relationships, economic stability, physical, mental stimulation and responsibility with their own existence. In the Social Dimension, the older adult sometimes finds satisfaction in solitude by feeling rejected by a society that does not need it. The older adult may have the impression that the stream of life is flowing without it, which has been reduced to a mere spectator. In reality it does not have to be this way, the positive solution of the crisis of retirement is forced, to avoid that the old man inevitably ends up in the two more painful aspects of the life; Boredom and loneliness. Lacub and Arias (2010) point out that physical-intellectual activity favor the well-being and quality of life of individuals, making them feel motivated and proud; To understand life as an experience of enjoyment, creations and freedom, in the full development of the potential of the human being for its realization and improvement of the quality of individual social life, through the practice of physical, intellectual or recreational activities. As for the Psychological dimension, illness and physical deficit are often accompanied by psychological and affective disorders such as depression, latent anxiety about the future, decreased relationships and contact with social activities that directly affect the individual's well-being. According to Anderson (1975) well-being is translated as being well, adapted, functional, satisfied and comfortable. It is a function of self-acceptance, having a purpose in life, maintaining positive relationships with others, etc. San Martin and Pastor (2001), indicates that the quality of life has a component related to the individual's feeling and perception of his life.

Perceptions of oneself in old age depend on how one's own personal reality is perceived, so that it depends not only on the capacities that each subject has but on the evaluation he makes of it.

The way a person is described in old age can vary according to the events of life, their ability to deal with them satisfactorily and family functionality. The role and position of older persons in the family and in society have had transitions according to the degree of social development, from the primitive community and the tribes, where the elders were venerated and played an important role within those societies. Until our days when the great scientifictechnical revolution, among other causes, requires us, through various factors, to give way to a large part of its functions and to take care of other less important ones.

It influences one's appreciation and appreciation of oneself in old age of how one's own personal reality is perceived and how one perceives one's family functionality. Therefore, one of the most serious problems that threaten the elderly is the fact that they find it harder to find for themselves some clearly defined role that makes them feel good and also to play it in their main social structure: the family. The latter is considered as the main social system of the older adult as it provides social, functional, economic or material support, affective and assistance in various forms.

Each person has a concept of the self and in function of it, processes and organizes the information of its context in a structure that provides the basis of principles to act in the present and in the future, this is how the subject maintains and develops A basic outline of his own self-perception. According to Lehr, U. (2004), the character of this self- 
perception can be taken as a predictor to know what changes the subject will follow in the necessary readjustment. Your appreciation and appreciation of yourself in old age depends on how you perceive your own personal reality that depends on multiple factors in this age. In this way, the realization of a behavior depends not only on the capacities that each subject has (psychophysical condition), but on the evaluation he makes of it.

Taking into account the above, the following questions arise: What is the level of self-perception that the older adult has about their quality of life?

The results of this work will allow the Ministry of Social Development to propose actions in this colony to contribute to improving the living conditions of adults over 70 and over.

\section{Materials and Methods:-}

In order to respond to these questions, the general objective of this work is to determine the self-perception about the quality of life of the older adult who attends the Polvorín Community Center to carry out intervention actions that improve their living conditions according to their real needs. In order to achieve comprehensive care and promote self-care.

It is a non-experimental, quantitative, cross-sectional descriptive research, Hernández et al (2014). The sample was taken from the group of older adults who attend the Community Center of Polvorín colony specifically to the "Club of the Elderly" belonging to the Municipal DIF of Campeche and sponsored by the Secretariat of Social Development within the program for the care of adults over 70 and plus. The inclusion criterion was that they belonged to the age group and attended the "Senior Adult Club". The sample was obtained by intentional nonprobabilistic sampling; it consisted of 50 elderly adults, of which 28 were women (56\%) and 22 were men (44\%); The mean age was 78 years, with a range between 70 and 89 years of age; The majority with married marital status and $41(82 \%)$ work outside the home.

Table 1:- Sociodemographic variables of the sample.

\begin{tabular}{|c|c|l|l|}
\hline \multicolumn{3}{|c|}{ Sociodemographic Variables of the Elderly } \\
\hline Gender & Female & 28 & $56 \%$ \\
& Male & 22 & $44 \%$ \\
\hline Age & $70-79$ & 31 & $62 \%$ \\
& $80-89$ & 19 & $38 \%$ \\
\hline Marital status & Single & 5 & $10 \%$ \\
& Separated & 3 & $6 \%$ \\
& Widower & 13 & $26 \%$ \\
& Divorced & 1 & $2 \%$ \\
& Married & 28 & $56 \%$ \\
\hline \multirow{2}{*}{ Work } & Yes & 41 & $82 \%$ \\
& No & 9 & $18 \%$ \\
\hline
\end{tabular}

The instrument called the Brief Questionnaire on Quality of Life was implemented (CUBRECAVI) (FernándezBallesteros and Zamarrón, 2007), measures the quality of life in a multidimensional way through nine components defined according to the aspects that may affect the quality of life Quality of people's lives. These components are: health (objective, psychic and subjective), social integration, functional skills, activity and leisure, environmental quality, satisfaction with life, education, income and social and health services. In the concept of Quality of Life is commonly referred to two key dimensions, precisely the objective dimension and the subjective dimension. The first refers to the material and socio-environmental conditions that a particular person has, such as health, housing, income, among others. The second refers to the way in which people perceive and signify such conditions. Stewart and King (1994) point out that quality of life is in itself the subjective assessment that people make of their situation. It was applied to each of the older adults individually in two-hour sessions for two months

\section{Results:-}

Coming up next, the results are presented by components of the most relevant findings of the research, describing and analyzing the subjective aspects of the quality of life obtained through the instrument and an in-depth interview 
that was carried out with reference to the Quality Questionnaire Life, because this one does not offer an overall score. We worked only by interpreting the frequency of the degree of satisfaction of each component. (See table 2)

Table 2:- Subjective result Quality of Life Questionnaire.

\begin{tabular}{|l|c|c|c|c|c|c|c|}
\hline \multirow{2}{*}{} & \multicolumn{2}{|c|}{ Total population } & \multicolumn{4}{c|}{ Population Gender } \\
\cline { 2 - 7 } & OPTION & $\begin{array}{c}\text { OLDER } \\
\text { ADULTS }\end{array}$ & $\%$ & MEN & $\%$ & WOMEN & $\%$ \\
\hline \multirow{3}{*}{ HEALTH } & Very Satisfied & 12 & $24 \%$ & 4 & $8 \%$ & 8 & $16 \%$ \\
& Somewhat satisfied & 28 & $56 \%$ & 9 & $18 \%$ & 19 & $38 \%$ \\
& Not satisfied & 10 & $20 \%$ & 9 & $18 \%$ & 1 & $2 \%$ \\
\hline SOCIAL & Very satisfied & 26 & $52 \%$ & 9 & $18 \%$ & 17 & $34 \%$ \\
INTEGRATION & Somewhat satisfied & 14 & $28 \%$ & 8 & $18 \%$ & 6 & $12 \%$ \\
& Not satisfied & 10 & $20 \%$ & 5 & $10 \%$ & 5 & $10 \%$ \\
\hline FUNCTIONAL & Very good & 2 & $4 \%$ & 1 & $2 \%$ & 3 & $6 \%$ \\
SKILLS & good & 32 & $64 \%$ & 10 & $20 \%$ & 22 & $44 \%$ \\
& Regular & 12 & $24 \%$ & 8 & $16 \%$ & 6 & $12 \%$ \\
& Bad & 4 & $8 \%$ & 3 & $6 \%$ & 2 & $4 \%$ \\
\hline ACTIVITY AND & Very Satisfied & 21 & $42 \%$ & 12 & $24 \%$ & 9 & $18 \%$ \\
LEISURE & Somewhat satisfied & 18 & $36 \%$ & 8 & $16 \%$ & 10 & $20 \%$ \\
& Not satisfied & 11 & $22 \%$ & 2 & $4 \%$ & 9 & $18 \%$ \\
\hline ENVIRONMENTAL & Very Satisfied & 19 & $38 \%$ & 8 & $16 \%$ & 11 & $22 \%$ \\
QUALITY & Somewhat satisfied & 24 & $48 \%$ & 10 & $20 \%$ & 14 & $28 \%$ \\
& Not satisfied & 7 & $14 \%$ & 4 & $8 \%$ & 3 & $6 \%$ \\
\hline SATISFACTION & Very Satisfied & 38 & $76 \%$ & 19 & $38 \%$ & 19 & $38 \%$ \\
WITH LIFE & Somewhat satisfied & 10 & $20 \%$ & 3 & $6 \%$ & 7 & $14 \%$ \\
& Not satisfied & 2 & $4 \%$ & 0 & $0 \%$ & 2 & $4 \%$ \\
\hline HEALTH & Very Satisfied & 14 & $28 \%$ & 6 & $12 \%$ & 8 & $16 \%$ \\
SERVICES & Somewhat satisfied & 21 & $42 \%$ & 10 & $20 \%$ & 11 & $22 \%$ \\
& Not satisfied & 15 & $30 \%$ & 6 & $12 \%$ & 9 & $18 \%$ \\
\hline
\end{tabular}

Regarding the Health Component, in the total population of 50 older adults, satisfaction level 12 (24\%) participants were very satisfied, of which $4(8 \%)$ are men and $8(16 \%)$ are satisfied. Are women, while $28(56 \%)$ expressed feeling somewhat satisfied, $9(18 \%)$ men and $38 \%$ women; And only $10(20 \%)$ of older adults answered that they were not satisfied. The older adults interviewed are aware of the physical changes they experience as their age advances and their health concept is very fragile but there is a great interest in continuing their daily activities in order to be productive and maintain social and economic relations. In terms of functionality, older adults in the sample retain their independence, although they require partial aids to perform activities involving motor functions. It seems that the cognitive and sensory functions are preserved, despite the aids that at the motor level might require

In the distribution of the population by gender, a higher percentage of satisfaction was observed in the female group compared to the male group. As far as physical health is concerned. Most people do not have suffered before the age of 60, they currently have muscular and rheumatic diseases but in the afternoons in the Club of the Elderly the staff give them three times a week Physical Exercise and they consider that it helps them, and even they practice when the teacher is not there.

We found in the Social Integration Component, that the total population of elderly shows to be very satisfied. 20 $(56 \%)$ of older adults feel very satisfied in their family life and feel valued, somewhat satisfied are $14(28 \%)$, because they express that the main causes of family conflicts are related to money or not valued by their family, and the difficult personality of the spouse and 10 seniors corresponding to $20 \%$ of the total population indicate that they are not usually visited by their children and other relatives. And consider the "Adult Club" a place where you feel accompanied and can feel affection of friendship, it is interesting that they are friends of at least 25 years and that they themselves have been inviting and motivated to attend. We observed that in the distribution of the population by gender the female group presents a percentage of $34 \%$ with respect to very satisfied and in the group of males very satisfied and somewhat satisfied both options with $8(16 \%)$, all affirm to have constant and frequent 
communication With his friends. Among the activities they share with their friends are: talking, attending group activities, religious activities, craft courses or improvement.

Functional skills, understood as the skills that allow them to be autonomous and useful people. The results show that most of the participants consider their functional abilities favorable, since the total population report feeling good 34 (64\%). Being 22 (44\%) the female population and $10(20 \%)$ male population, they consider having no problems to perform their physical care, walking fix their house and even most work outside the home in activities as supermarket dispatchers and most carry out bagging Of species, these activities are done in the Club of the Elderly that belongs to the Municipal Government. Twenty-four percent (24\%) of 12 seniors reported experiencing difficulties in performing activities and $4(8 \%)$ said they had many difficulties, but the latter said they did not "leave" and it was better to adopt a positive attitude. One of the aspects taken up within the present component in its subjective dimension is whether the participants could stand on their own and the level at which they could do it. This question shows if there is also a relationship between the skills referred to by the participants and how they perceive what they allow them to do as people, self motivating and generating positive attitude on their own.

Regarding the Activity and Leisure component, it refers to the physical activity performed or not by the elderly in the old age, starting from the idea that these are important for a better state of health and quality of life. Of the total population, $21(42 \%)$ reported being very satisfied and $18(36 \%)$ somewhat satisfied, only $11(22 \%)$ reported satisfaction. It should be noted that this group of older adults through the Municipal Government receive physical exercise classes, crafts and give them regional dance classes. This they do in their free time and are activities in which they obtain social and physical benefits. However, the female group of $9(18 \%)$ who expressed Unsatisfied stated that they chose this option because they wanted to spend more time on these activities that are done in the community center but can not because they have to take care of their grandchildren. The activities of Leisure that they realize is to watch television but only they do it occasionally, since it has to carry out their housework or to make damages in house and that occupies their free time. In general, they state that they are very satisfied with the way they occupy their time.

On the other hand, for the environmental quality component, considered as the level of satisfaction of the elderly with a series of objective aspects of their dwelling, as well as general satisfaction with it (Fernández-Ballesteros and Zamarrón, 2007). The majority said that they are somewhat satisfied 24 (48\%). When they were questioned on this point, they said that there are many steps to reach their home, and that their homes are in the hills, and it costs them much effort to get to where they do their jobs or to this Community Center. 19 (38\%) very satisfied this degree of satisfaction in general with all the elements that make up the dwelling of the participants,

Turned out to be positive as the participants who stated they were entirely satisfied with it. This aspect is fundamental in the quality of life of the elderly, since it directly affects

In their subjective well-being. And 7 (14) dissatisfied. Valdez and Cubillas (2005), highlight how the physical and environmental aspects,

Such as housing, influence the autonomy, well-being and social participation of older people. That is, their conditions influence the quality of life they may have.

For the component of Life Satisfaction, considered very important since in this the elderly are perceived with respect to their own life, this makes the attitude that they have toward the aging. The results show that the majority of the participants were satisfied with their lives. 76\% (38 older adults) reported having great satisfaction, with the female group 19 (38\%) and 18 (38\%) the male group; 5 (10\%) older adults said they had some satisfaction, and only $2(4 \%)$ reported not being satisfied with life.

Finally, for the component of uses of health services, the frequency with which they came to health services and the satisfaction they have with them. A significant number of respondents reported using these services 46 (92\%), while $8(4 \%)$ did not use them. Likewise, the level of satisfaction of the elderly with respect to the use of services was questioned 
Social and health; we found that $14(28 \%)$ were very satisfied with these services, 21 (42\%) said they were somewhat satisfied and $15(30 \%)$ said they were not satisfied with those services.

The components most valued by the total population were health as first choice; Life satisfaction as a second option and as a third option the social integration component.

In the distribution of the population by gender, both men and women chose health as the first option, in the second option life satisfaction and in the third option the social integration component stand out differences as the female group values social and family relationships more, While the male group chose to fend for itself.

In general, for the population under investigation, the average level of quality of life is determined by the health component and social and family relationships. The determinants that most influence their quality of life are the level of independence or dependency to carry out their activities, economic dependence, the presence of diseases and / or their complications, social isolation, widowhood, mistreatment and lack of access to medical services.

\section{Discussion:-}

Definitely the aging process brings with it a series of multidimensional changes that characterize the self-perception that the older adult has. In general, the data in this research reveal that the elderly participants have a "good" selfperception of their positive quality of life, this is explained in affirmations where it gives more importance to being, than to do or have, that in the family their presence allows to value more the simple things of life. Undoubtedly the attitudes of the elderly have to do directly with the way in which their life experiences are perceived, valued and integrated, has a great impact on the subjective satisfaction of their own lives, they seek alternatives and useful activities for him and For society that help them feel useful and empowering their self-esteem. And therefore in their general quality. Aging perceives it as positive because their functional abilities allow them to take care of themselves and even care for their partner and grandchildren, they feel loved by their family. It is influenced by the fact that most of them work in various activities and that allows them to remain socially integrated, economically productive and physically active, although most suffer from blood pressure and diabetes, they say they know how to live with the disease, that is, they take care of themselves and control themselves. It should be mentioned that in the Club of the Elderly that attend they receive talks on prevention and self-care of diseases specific to the age.

The results found allow us to know the reality of the way in which the adult person is perceived, and these results allow us to make the evaluation. The latter is the process known as self concept and it depends on the way each individual tends to face life, to value oneself and others. Of this evaluation depends to a large extent on the way in which each one faces the conflicts and difficulties of life when a person reaches old age and that they are an important factor for the adaptation to a vital period. There are several studies suggesting that men had a quality of life in older age than that of women (Camargos et al., 2007; Drumond et al., 2011). However, our results showed the existence of differences between men and women in certain scales evaluated by CUBRECAVI, in such a way that women obtain scores indicative of a higher quality of life in the components of health, social integration and skills Functional, as well as less complaint about different physical symptoms and greater independence than men. These results do not agree with previous studies, where older men appear to have lower physical problems at advanced ages (Lym, Paik and Park, 2008). Men scored higher than women in the activity and leisure component and environmental quality. Both groups are satisfied with their quality of life.

With respect to intervention actions that improve their living conditions according to their real needs in order to achieve comprehensive care and promote their self-care. These results demonstrate that they should continue with the activities they perform in the Senior Adult Club since the workshops in which the older adults participate according to their preferences strengthen them and promote the development of their individual role and it is necessary to implement networks with which the older adult counts to sustain their daily life. To integrate the older adult in some tasks that he himself considers capable of carrying out and teaching others. As well as training regarding social skills and mechanisms of adaptation of older adults against losses in physical, psychological and social aspects. It is observable that if the elderly is self-reliant, he/she feels satisfied with his / her relationship with his / her family, and is supported by a peer social group. This makes him consider himself useful and not a charge to the family and society in which Is developed and allows it to be functional, it is essential not to lose what was gained with this group of adults reinforcing and implementing actions. 


\section{References:-}

1. Andersson, L. y Stevens, N. (1993) Associations between early experiences with parents and well-being in old age. Journals of Gerontology, May Vol. 48(3):109-116.

2. Camargos, M.C., Machado, C.J. y Rodrigues, R.N. (2007). Disability life expectancy for the elderly, city of São Paulo, Brazil, 2000: Gender and educational differences. Journal of Biosocial Science, 39, 455-463

3. Consejo Nacional de Población (2013). Proyecciones de la Población de México 2010-2050. México, CONAPO

4. Drumond, F., Guevara, P., Lebrao, M., Oliveira, Y. y Ferreira, J. (2011). Gender Differences in Life Expectancy and Disability-Free Life Expectancy Among Older. Women's Health Issues, 21, 64-70.

5. Fernández-Ballesteros, R., Moya, R., Iñiguez, J. y Zamarrón, M.D. (1999): Qué es psicología de la vejez. Madrid: Morata.

6. Fernández-Ballesteros, R. y Zamarrón, M.D. (2007). Cubrecavi. Cuestionario breve de calidad de vida. Madrid: TEA Ediciones

7. GARCIA HERNANDEZ. Enfermería Geriátrica. España. 2da Ed. Elsevier Masson. 2006. p. 27,82 - 84.

8. Hernández Sampieri, et al. (2014) Metodología de la Investigación. 6 ed. México: McgrawHill.

9. Instituto Nacional de Salud Pública (2012) Evaluación de impacto del programa 70 y Más 2009 disponible para consulta en http://www.2006-2012.sedesol.gob.mx/es/SEDESOL/70_y_mas INSP (consulta julio 2016)

10. INAPAM (2010) Por una cultura del envejecimiento. Cuadernos de SEDESOL. Gobierno Federal México.

11. Iacub, Ricardo; Arias, Claudia Josefina El empoderamiento en la vejez Journal of Behavior, Health \& Social Issues, vol. 2, núm. 2, noviembre-abril, 2010, pp. 25-32 Asociación Mexicana de Comportamiento y Salud, A. C. México

12. Lehr, U. (2004). Calidad de vida, satisfacción con la vida, envejecimiento satisfactorio y bienestar subjetivo. Rev. Esp. Geriatr. Gerontol., (Suppl. 3): 2-7

13. Lym, J., Paik, N. y Park, W. (2008). The effect of age and sex on physical function and quality of life in Korean elderly: The Korean Longitudinal Study on Health and Aging. Archives of Physical Medicine and Rehabilitation, 89, E52.

14. Mauk Kristen (2008). Enfermería Geriátrica. USA. Ed. Mc Graw Hill Interamericana. p. 556 - 558.

15. Organización Mundial de la Salud. (2014) Repercusión mundial del envejecimiento en la Salud [documento en línea]. Disponible en: htt://www.who.int/features/qa/42/es/index.html Recuperado. 15 de abril 2017.

16. Organización Mundial de la Salud (2004) Promoción de la salud mental, Informe Compendiado, París, OMS, (2004).

17. San Martín H, Pastor U. (2001) Epidemiología de la vejez. 1a ed. México: McGraw-Hill Interamericana.

18. Stewart, A. y King,A. (1994). "Conceptualizing and Measuring Quality of Life in Older Populations". En: ABELES, R., GIFT, H., y ORY, M., (Coords) (1994). Aging and Quality of life. New York: Assistant.

19. Valdez, E., Román, R. \& Cubillas, M. (2005). Análisis de la oferta de servicios para adultos mayores y sus necesidades manifiestas. Psicología y Salud,15, 127-133. 